\title{
The Role of the OCP and Syllable Structure in Makkan Arabic Hypocoristics
}

\author{
Mahasen Hasan Abu-Mansour \\ Department of English, College of Social Sciences, Umm Al-Qura University, Makkah, Saudi Arabia
}

Copyright $(2019$ by authors, all rights reserved. Authors agree that this article remains permanently open access under the terms of the Creative Commons Attribution License 4.0 International License

\begin{abstract}
This paper shows that the failure of names related to glide-medial and glide-final roots to form Pattern I $\mathrm{C}_{1} \mathrm{aC}_{2} \mathrm{C}_{2} \mathrm{uuC}_{3}$ hypocoristics is due to the effects of the OCP and syllable structure constraints, respectively. Names related to roots with medial [w] fail to form Pattern I hypocoristics since the sequence -wuu-violates the OCP. Names related to glide final roots [y] or [w] form $\mathrm{C}_{1} \mathrm{aC}_{2} \mathrm{C}_{2} \mathrm{u}$ hypocoristics where the deletion of the final glide avoids violation of syllable structure constraints in the language. The Optimality-Theoretic account in this paper demonstrates that there is only one native pattern of hypocoristic formation in Makkan Arabic with two manifestations, $\mathrm{C}_{1} \mathrm{aC}_{2} \mathrm{C}_{2} \mathrm{uuC}_{3}$ and $\mathrm{C}_{1} \mathrm{aC}_{2} \mathrm{C}_{2} \mathrm{u}$. Syllable structure constraints and the OCP account for the apparent differences between these two forms. Data from Makkan Arabic hypocoristic formation show that native speakers can factor out the root consonants from the actual name and use them in hypocoristic formation.
\end{abstract}

Keywords Arabic, Hypocoristic Formation, Makkan Arabic, OCP, Syllable Structure, the Root

\section{Introduction}

In several Arabic dialects including Makkan Arabic, (MA, henceforth) the main pattern of Hypocoristic Formation, (HF, henceforth) is disyllabic $\mathrm{C}_{1} \mathrm{aC}_{2} \mathrm{C}_{2} \mathrm{uuC}_{3}$. The vowels are invariably /a/ and /uu/, while the consonants coincide with those of the actual name. The first syllable in the pattern is a CVC syllable with germination of the second consonant of the root. Stress falls on the second syllable of the hypocoristic in accordance with the general rule of stressing final superheavy syllables in the majority of the Arabic dialects. This pattern is primarily used for hypocoristics related to triconsonantal roots with no glides. For instance, hassuun is the acknowledged nickname for names such as hasan, muћsin, $\hbar u s e n$, all of which are related to the root $\sqrt{ } \hbar s n$.
However, names related to triconsonantal roots with medial or final glides fail to form $\mathrm{C}_{1} \mathrm{aC}_{2} \mathrm{C}_{2} \mathrm{uuC}_{3}$ hypocoristics. First, glide-medial roots exhibit dual behavior with respect to HF of Pattern I. If the medial glide of the root is $[\mathrm{w}]$, the name fails to take a hypocoristic of Pattern I, for example, the name nawaal comes from the root $\sqrt{ }$ nwl 'achievement' fails to take Pattern I *nawuula as a nickname. If on the other hand, the medial glide is [y], the name does form a hypocoristic of Pattern I. The name Saayfa from the root / $Y y \int /$ 'living' forms Sayyuuf as its hypocoristic. Second, names related to glide-final roots fail to form Pattern I, whether the final glide is [w] or [y]. Thus, the names faadyah and zakiyyah fail to form Pattern I hypocoeistics * fadduuw and *zakkuuy, respectively.

The two names are related to the roots $\sqrt{ } \int d w$ 'chanting' and V $z k y$ 'righteous', respectively. Instead, these two names form Pattern two hypocoristics faddu and zakku, respectively. The templatic shape of Pattern II hypocoristics is $\mathrm{C}_{1} \mathrm{aC}_{2} \mathrm{C}_{2} \mathrm{u}$. The final glide never appears in the hypocoristic.

The present Optimality-Theoretic analysis provides a straightforward account for the failure of glide-medial and glide-final roots to form $\mathrm{C}_{1} \mathrm{aC}_{2} \mathrm{C}_{2} \mathrm{uuC}_{3}$ hypocoristics. The first follows from the OCP effects while the second is enforced by constraints on MA syllable structure. These constraints are well motivated and independently needed in the language.

The other major issue in the paper is the claim that the two most frequently used patterns of $\mathrm{HF}, \mathrm{C}_{1} \mathrm{aC}_{2} \mathrm{C}_{2} \mathrm{uuC}$, and $\mathrm{C}_{1} \mathrm{aC}_{2} \mathrm{C}_{2} \mathrm{u}$ are structurally related and represent two variants of one pattern. There is, however, a division of labor in the use of these patterns: $\mathrm{C}_{1} \mathrm{aC}_{2} \mathrm{C}_{2} \mathrm{u}$ pattern is followed by exactly those roots that fail to follow Pattern I, $\mathrm{C}_{1} \mathrm{aC}_{2} \mathrm{C}_{2} \mathrm{uuC}_{3}$, i.e. glide-final roots. Abu-Mansour [1, 2, 3] describe these forms of $\mathrm{HF}$ in MA as two separate patterns, and falls short of uncovering the underlying basic similarities of the two forms as well as their differences. In the present analysis, evidence for the claim that we are dealing with two manifestations of one pattern comes from the explanation of the same problems that led earlier 
analyses to challenge the primacy of the lexical root and to assume an output root for HF [4]. In this paper, the failure of glide-medial and glide-final roots to form $\mathrm{C}_{1} \mathrm{aC}_{2} \mathrm{C}_{2} \mathrm{uuC}_{3}$ hypocoristics is shown to result from the domination of the faithfulness constraints by the OCP and by constraints on syllable codas in MA, respectively. This in itself leads to a very welcome result of the analysis: what has been referred to as Pattern $\mathrm{II} \mathrm{C}_{1} \mathrm{aC}_{2} \mathrm{C}_{2} \mathrm{u}$ in Abu-Mansour $[1,2,3]$ and in Davis and Zawaydeh [4] will in fact provide the only possible way of forming hypocoristics for names related to glide-final roots. In OT terms, this will be the result of only two of the constraints in the grammar of MA hypocoristics occupying different places in the constraint hierarchy.

The remainder of this article is organized as follows. Section 2 introduces the two patterns of HF in MA $\mathrm{C}_{1} \mathrm{aC}_{2} \mathrm{C}_{2} \mathrm{uuC}_{3}$ and $\mathrm{C}_{1} \mathrm{aC}_{2} \mathrm{C}_{2} \mathrm{u}$, as well as exceptions to Pattern I. Section 3 provides a detailed analysis of hypocoristics related to triconsonantal roots and supports the fact that only the root consonants are referenced in the hypocoristic. It establishes the role of the OCP and syllable structure constraints in explaining the failure of glide-medial and glide-final roots to form $\mathrm{C}_{1} \mathrm{aC}_{2} \mathrm{C}_{2} \mathrm{uuC}_{3}$ hypocoristics. Section 4 summarizes the similarities as well as the differences between the two patterns in terms of constraint ranking capitalizing on the idea that $\mathrm{C}_{1} \mathrm{aC}_{2} \mathrm{C}_{2} \mathrm{u}$ is, in fact, a variant of $\mathrm{C}_{1} \mathrm{aC}_{2} \mathrm{C}_{2} \mathrm{uuC}_{3}$ selected by glide-final roots. Section 5 summarizes the main points of the paper.

\section{Basic Patterns of HF in Makkan Arabic}

Makkan Arabic utilizes two patterns of hypocoristics $\mathrm{C}_{1} \mathrm{aC}_{2} \mathrm{C}_{2} \mathrm{uuC}_{3}$ and $\mathrm{C}_{1} \mathrm{aC}_{2} \mathrm{C}_{2} \mathrm{u}$. They are referred to as Pattern I and Pattern II, respectively. Examples of the two patterns with their CV-Templates are given in (1).

(1) Main patterns of hypocoristics in Makkan Arabic

\begin{tabular}{|c|c|c|c|}
\hline & Name & Hypocoristic & Root \\
\hline P. I & xadiijah & $\begin{array}{c}\text { xadduuǰ (a) } \\
\text { C1aC2C2uuC3 }\end{array}$ & $\begin{array}{c}\sqrt{\mathrm{xd} \mathrm{j}} \\
\text { 'tender' }\end{array}$ \\
\hline P. I & ћanaan & $\begin{array}{c}\text { hannu } \\
\text { C1aC2C2u } \\
\end{array}$ & $\begin{array}{c}\sqrt{\hbar n} \\
\text { 'affectionate' }\end{array}$ \\
\hline
\end{tabular}

Among the two patterns, $\mathrm{C}_{1} \mathrm{aC}_{2} \mathrm{C}_{2} \mathrm{uuC}_{3}$ is the most common and frequently used by all speakers of $\mathrm{MA}$ and several other dialects of Arabic. $\mathrm{C}_{1} \mathrm{aC}_{2} \mathrm{C}_{2} \mathrm{uuC}_{3}$ hypocorostics have been the focus of several studies [1, 2, 3], [5, 4], and [6]. As for Pattern II, it is less common than Patten I, and is only used for certain names. A detailed discussion of Pattern II in MA is found in Abu-Mansour [1, 2, 3].

\subsection{Pattern I: $\mathrm{C}_{1} \mathrm{aC}_{2} \mathrm{C}_{2} \mathrm{uuC}_{3}$ Hypocoristics}

Pattern I hypocoristics is primarily used for names that are associated with sound triconsonantal roots that include no glides. The three consonants always appear in the actual name as well as in the corresponding hypocoristic. Representative examples appear in (2):

(2) Hypocoristics of names related to sound triconsonantal roots

\begin{tabular}{|c|c|c|c|}
\hline & Name & Hypocoristic & Root \\
\hline a. & hasan & ћassuun & $\sqrt{\hbar s n}$ \\
\hline b. & muћammad & ћammuuda & $\sqrt{\hbar \mathrm{hmd}}$ \\
\hline c. & Paћmad & ћammuuda & $\sqrt{\text { hmmd }}$ \\
\hline d. & PiStidaal & Sadduul(a) & $\sqrt{ } \varsigma \mathrm{dl}$ \\
\hline e. & Panas & Pannuus & $\sqrt{ } \mathrm{Pns}$ \\
\hline f. & farћaan & farruuћ(a) & $V_{\text {frh }}$ \\
\hline
\end{tabular}

The examples in (2) reveal the main linguistic features of Pattern I. First, only the root consonants are realized in the hypocoristic form; affixal and epenthetic material do not appear in the hypocoristic. The prefix [m] in (2b), the epenthetic [?] in (2c \& d), the infix [t] in (2d) as well as the suffix [an] in (2f) do not appear in the hypocoristic. However, [?] surfaces in (2e) since it is part of the root. Since only root consonants are realized in the hypocoristic, several names may share the same nickname as in (2b) and (2c). Finally, the suffix [a] optionally follows the hypocoristic, and is not decided by the gender associated with the name.

In addition, names related to quadrilateral and biconsonantal roots form Pattern I hypocoristics. For instance, the names Pibraahiim and ћanaan come from the roots $\sqrt{b r h m}$ 'steadfast' and $\sqrt{\hbar n}$ 'affection', respectively. Their corresponding nicknames are barhuum and

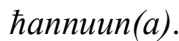

However, the analysis in this paper will include only Pattern I hypocoristics of names related to triconsonantal sound roots as well as the exceptions to this pattern, i.e., glide-medial and glide-final roots.

\subsection{Exceptions to Pattern I}

\subsubsection{Glide-medial Roots}

Names related to glide-medial roots exhibit dual behavior with respect to HF of Pattern I. If the medial glide of the root is [w], the name fails to take a hypocoristic of Pattern I as in (3).

\section{(3) Medial [w] and Pattern I}

\begin{tabular}{|c|c|c|c|}
\hline & Name & Hypocoristic & Root \\
\hline a. & fawziyya & *fawwuuz & $/ \mathrm{fwz} /$ \\
\hline b. & nawaal & *nawwuula & $/ \mathrm{nwl} /$ \\
\hline c. & Panwar & *nawwuur & $/ \mathrm{nwr} /$ \\
\hline
\end{tabular}

If, on the other hand, the medial glide is [y], the name forms Pattern I hypocoristic just like names related to regular triconsonantal roots: the glide appears in the 
hypocoristic, as the examples in (4) illustrate:

(4) Medial [y] and Pattern I

\begin{tabular}{|c|c|c|c|}
\hline & Name & Hypocoristic & Root \\
\hline a. & bayaan & bayyuun & /byn/ \\
\hline b. & Saayfa & Gayyuu & $/$ / yf/ \\
\hline
\end{tabular}

\subsubsection{Glide-final Roots}

All names related to glide-final roots do not form Pattern I hypocoristics. This includes roots with both glides [y] and [w]. Representative examples of this category are given in (5):

(5) Glide-final roots and Pattern I

\begin{tabular}{|c|c|c|c|}
\hline & Name & Hypocoristic & Root \\
\hline a. & faza & $*$ Jazzuuw & $\sqrt{\int \mathrm{zw}}$ \\
\hline b. & Jaadyah & * fadduuw & $\sqrt{\int d w}$ \\
\hline c. & zakiyyah & *zakkuuy & $\sqrt{z k y}$ \\
\hline d. & nada & *nadduuy & $\sqrt{ }$ ndy \\
\hline
\end{tabular}

\subsection{Pattern II: $\mathrm{C}_{1} \mathrm{aC}_{2} \mathrm{C}_{2} u<u>$ Hypocoristics}

Pattern II of hypocoristics is mainly used for names related to glide-final roots, both [w] and [y]. This is exactly the same group of names that fail to form Pattern I hypocoritics because of the structure of the roots with which they are associated (cf. the examples in (5). Examples of this category along with their Pattern II hypocoristics are given in (6):

(6) Pattern II Hypocoristics

\begin{tabular}{|c|c|c|c|}
\hline & Name & Hypocoristic & Root \\
\hline a. & faza & fazz+u & $V_{\text {fzw }}$ \\
\hline b. & faadyah & fadd $+u$ & $\sqrt{\text { ddw }}$ \\
\hline c. & zakiyyah & zakk+u & $V_{\text {zky }}$ \\
\hline d. & nada & nadd $+u$ & $V_{\text {ndy }}$ \\
\hline
\end{tabular}

In addition to glide-final roots, names related to biconsonantal geminate roots have the option of forming Pattern II hypocoristics as the examples in (7) show.

(7) Biconsonantal Roots and Pattern II

\begin{tabular}{|c|c|c|c|}
\hline & Name & Hypocoristic & Root \\
\hline a. & dalaal & Dallu & $\sqrt{ } \mathrm{dl}$ \\
\hline b. & hanaan & hannu & $\sqrt{ }$ hn \\
\hline
\end{tabular}

\section{Analysis}

This section presents an Optimality-Theoretic analysis of Pattern I and Pattern II hypocoristics. The analysis will focus on the following points. First, the similarities between the two patterns as well as the differences will be stated in OT terms. Second, it explains the role of the OCP and syllable structure in accounting for Pattern II hypocoristics and in explaining the exceptions to Pattern I. Third, the analysis will demonstrate that what has been referred to as a separate pattern, Pattern $\mathrm{II} \mathrm{C}_{1} \mathrm{aC}_{2} \mathrm{C}_{2} \mathrm{u}[1,2$, 3], and [5] is in fact a variant of Pattern I. The structure of $\mathrm{C}_{1} \mathrm{aC}_{2} \mathrm{C}_{2} \mathrm{u}$ (Pattern II) is minimally different from $C_{1} a C_{2} C_{2} u u C_{3}$ (Pattern I). In OT terms, this difference will be the result of only two of the constraints in the grammar of Arabic hypocoristics occupying different places in the constraint hierarchy. Pattern II provides the only possible way of forming hypocoristics for names related to glide-final roots.

\subsection{Analysis of Pattern I $\mathrm{C}_{1} \mathrm{aC}_{2} \mathrm{C}_{2} u u \mathrm{C}_{3}$ Hypocoristics}

Hypocoristic formation in MA is a process that references the consonantal root. It involves considerable abstraction from the structure of the actual name. This is clear from hypocoristics of names in (1), (2), and (4) where only the root consonants are abstracted from the actual name and mapped into the hypocoristic pattern. No other structural property of the name survives in the hypocoristic.

The full name provides the base for HF. Native speakers have the ability to factor out the root consonants and leave behind non-root material, such as the vowels and affixes. In addition to the root consonants, the vowels of the pattern [aa] and [uu] form the other part of the input. The first property of this pattern is that all hypocoristics of this type surface with two syllables and each syllable is bimoraic. The specific realization of the two heavy syllables in the output of hypochoristics whether CVC or CVV, will be decided by the interaction of two of the markedness constraints. Second, the first consonant in the hypocoristic must coincide with the first root consonant and must end with the final consonant of the root (not the actual name). Third, the second consonant of the root is always geminated. The final important property of Pattern I hypocoristics is that only root consonants appear in the hypocoristic; affixal consonants are left out.

These properties will be accounted for using three types of constraints, Correspondence Constraints [7] and [8], Alignment Constraints [9], and Markedness Constraints [10] and [11]. The first two types of constraints are undominated in the grammar of Pattern I hypocoristics in MA.

\subsection{Correspondence Constraints}

(8) MAX-Rt Hypo(C)

Every root consonant must have a correspondent in the hypocoristic- no deletion.

\section{(9) DEP-Rt Hypo(C)}

Every consonant in the hypocoristic must have a 
correspondent in the root- no epenthetic or affixal material.

(10) $\operatorname{MAX}-\mathrm{IO}(\mu)$

Every mora of the input has a correspondent in the output.

\section{(11) IDENT-IO(V)}

Correspondent input and output vowels have the same specification for all features.

\subsection{Alignment Constraints}

(12) Align (Rt, L, Hypo, L)

The left edge (first consonant) of the root must be aligned with the left edge of the hypocoristic.

(13) Align (Rt, R, Hypo, R)

The right edge (last consonant) of the root must be aligned with the right edge of the hypocoristic.

\subsection{Markedness Constraints}

(14) ONSET

(15) *COMPLEX

(16) NO-LONG-V (*VV)

(17) GEMINATE $\left({ }^{*} \mathrm{GEM}\right)$

The faithfulness constraint in (8) requires that all root consonants are realized in the hypocoristic, while (9) ensures that only root consonants appear in the hypocoristic. The constraint in (10) requires that the four moras of the input be realized in the hypocoristic [7]. The long vowel of the first syllable in the input surfaces as short, however, the syllable maintains its weight and surfaces as a heavy CVC syllable. Since MA allows long vowels both in basic and derived structures, the occurrence of the CVC syllable in this case must be the effect of a restriction other than the one that bans long vowels in adjacent syllables [12]. It is, in fact, the ranking *VV $>>*$ GEM that insures a CVC syllable instead of CVV in this position.

The other two alignment constraints in (12) and (13) require that a hypocoristic form of this type starts with the first consonant of the root and ends with the last consonant, respectively.

The faithfulness constraints in (8), (9), (10), and (11) as well as the alignment constraints in (12) and (13), are all undominated constraints in the phonology of this pattern of hypocorisctics. The markedness constraints in (14) and (15) are also undominated in the language. They require syllable well-formedness in the output. Candidates with complex onsets or codas, and syllables that lack onsets are all ruled out in the language.

The following is a short OT account of the basic features of Pattern I. For example, hassuun is the nickname for

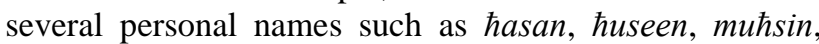
Pi $\hbar s a a n$, all of which are associated with the root $\sqrt{ } \hbar s n$.

The input to all hypocoristics of Pattern I includes the root consonants and the two bimoraic syllables of the pattern. The ranking in (18) establishes the role of the faithfulness and alignment constraints (8-13) in deciding the template shape of this hypocoristic form.

(18) MAX-Rt HYPO(C), DEP-Rt HYPO(C), MAX-IO( $\mu$ ), IDENT-IO(V), Align (Rt, L, Hypo, L), Align (Rt, R, Hypo, R) >> *GEM

Table 1 establishes the role of the faithfulness constraints in the grammar of this pattern. The actual hypocoristic is candidate (g). It obeys all constraints except the markedness constraint ${ }^{*} \mathrm{GEM}$, while each of the other candidates violates one or two of the faithfulness constraints. The full name muћsin has a non-root consonant, the prefix $m$-. Both candidates (a) and (b) are excluded for including this consonant. In addition, candidate (a) does that at the expense of deleting a root consonant [ $\hbar]$.

Another crucial aspect of the grammar of this pattern is the inalterability of the vowels in the pattern: [a] in the first syllable and [uu] in the second. The identity constraint IDENT-IO(V) warrants faithful mapping of the vowels of the input in both syllables. Both candidates (e) and (f) are not optimal: candidate (f) changes the identity of one vowel of the input while (e) incurs two violations of IDENT-IO(V) by reversing the order of the vowels of the input. This allows candidate (g) to surface as the actual hypocoristic by obeying all constraints including IDENT-IO(V).

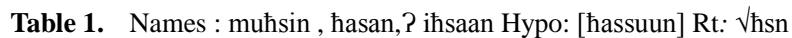

\begin{tabular}{|c|c|c|c|c|c|c|c|}
\hline 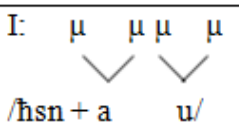 & $\begin{array}{l}\text { MAX-Rt } \\
\text { Hypo (C) }\end{array}$ & $\begin{array}{l}\text { DEP-Rt } \\
\text { Hypo (C) }\end{array}$ & $\begin{array}{c}\text { MAX-IO } \\
(\mu)\end{array}$ & $\begin{array}{l}\text { IDENT-IO } \\
\text { (V) }\end{array}$ & $\begin{array}{c}\text { Align } \\
\text { (Rt, L, } \\
\text { Hypo, L) }\end{array}$ & $\begin{array}{c}\text { Align } \\
\text { (Rt, R, } \\
\text { Hypo, R) }\end{array}$ & ${ }^{*} \mathrm{GEM}$ \\
\hline a. mas.suun & $* !$ & $* !$ & & & $* !$ & & $*$ \\
\hline b. maћ.suun & & $* !$ & & & $* !$ & & \\
\hline c. ha.suun & & & $* !$ & & & & \\
\hline d. has.nuu & & & & & & $* !$ & \\
\hline e. hus.saan & & & & $* ! *$ & & & $*$ \\
\hline f. $\quad$ has.siin & & & & $* !$ & & & $*$ \\
\hline g. has.suun & & & & & & & $*$ \\
\hline
\end{tabular}


The alignment constraints in (12) and (13) are obeyed by Pattern I hypocoristics. This explains why candidates (b) and (d) are not optimal despite their satisfaction of the rest of the constraints.

The ranking of the markednaess constraints *VV and *GEM in (19) and their interaction in Table 2 account for the realization of the first syllable of the pattern as a CVC.

(19) $* \mathrm{VV}>>* \mathrm{GEM}$

Table 2. Name: hasan Hypo: [hassuun]

\begin{tabular}{|l|c|c|c|}
\hline $\mathrm{I}: V^{\mu} v^{\mu}$ & $* \mathrm{VV}$ & $* \mathrm{GEM}$ \\
/hsn $+\mathrm{a} \quad \mathrm{u} /$ & & \\
\hline a. has.suun & $*$ & $*$ \\
\hline b. haa.suun & $* * !$ & \\
\hline
\end{tabular}

The upshot of the current analysis of triconsonantal roots is that given the input of the three root consonants and the two bimoaic syllables, the interaction of the three types of constraints in (8-17), will always result in a hypocoristic with the template $\mathrm{C}_{1} \mathrm{aC}_{2} \mathrm{C}_{2} \mathrm{uuC}_{3}$.

To summarize, this section has established two salient characteristics of the $\mathrm{C}_{1} \mathrm{aC}_{2} \mathrm{C}_{2} \mathrm{uuC}_{3}$ Pattern used for triconsonantal roots. First, only the root consonants are referenced in the hypocoristic. Second, the specific template of this pattern results from the satisfaction of all of the constraints relevant to the pattern. Apart from *VV $>>$ *GEM, the rest of the constraints are unranked with respect to each other. Thus, the optimal form must satisfy all of them.

\subsection{The Role of the OCP: Glide-medial Roots}

This section shows that the failure of the medial glide [w] to appear in Pattern I hypocoristics is an effect of the OCP. In Section 2.2.1, examples in (3) and (4) show that glide-medial roots behave in two different ways. No hypocoristics can be constructed for roots in which the glide is [w]. However, if the medial glide is [y], then the root is treated like any regular triconsonantal root giving Pattern I hypocoristic. We first consider roots with $[\mathrm{w}]$ and the impossibility of Pattern I hypocoristics for such roots.

(20) Examples are repeated in (20):

\begin{tabular}{|c|c|c|c|}
\hline & Name & Hypocoristic & Root \\
\hline a. & fawziyya & *fawwuuz & $/ \mathrm{fwz} /$ \\
\hline b. & nawaal & *nawwuula & $/ \mathrm{nwl} /$ \\
\hline c. & Panwar & *nawwuur $^{\text {naw }}$ & $/ \mathrm{nwr} /$ \\
\hline
\end{tabular}

Evidence for underlying $[\mathrm{w}]$ comes from related words where the glide surfaces, for instance, fawwaz 'to choose as a winner' and minawwir 'glowing'.

The failure of $[\mathrm{w}]$ to appear in hypocoristics for glide-medial names will be a consequence of a well-motivated constraint in the language, the OCP in (21):
(21) Obligatory Contour Principl (OCP)([13], [14, 15], [16])

Adjacent identical elements are prohibited.

The role of the OCP in Pattern I hypocoristics is that it specifies what constitutes possible onsets for the second vowel of the hypocoristic pattern. Simply stated, *wuu in glide-medial hypocoristics is not a well-formed sequence in the syllable structure of MA. In OT terms, they establish the domination of the markedness constraints and constraints on what constitutes permissible codas in MA.

In addition to the OCP, all the undominated constraints introduced for Pattern I apply here. A hypocoristic has to obey all of the undominated constraints (8-17). However, when there is a clash with the OCP, the form that does not violate the markedness constraint (OCP) is the one chosen. The ranking established in (22) and the interaction in Table 3 explain why names related to $w$-medial roots fail to form Pattern I hypocoristics. The markedness constraint outranks both the faithfulness and the alignment constraints.

\section{(22) OCP, IDENT-IO (V) >> MAX-Rt Hypo(C), DEP-Rt Hypo(C) $>>*$ GEM}

Candidate (a) in Table 3 is faithful to the underlying glide [w]; it however loses since it violates the high-ranking OCP that prohibits adjacent identical segments. Candidate (b) satisfies the OCP at the expense of violating the identity constraint of the template vowel [uu]. Candidate (c) satisfies the high ranking OCP by changing the underlying glide to [y] but does not win since fayyuuz is not the acknowledged hypocoristic for fawziyyah in MA. The constraint ranking in (22) explains the failure of the underlying glide to surface in the hypocoristic and thus the total failure of names related to glide-medial roots where the glide is [w] to have Pattern I hypocoristics.

Table 3. Name: fawziyyah *[fawwuuz]

\begin{tabular}{|l|c|c|c|c|c|}
\hline I: $\quad \mu \mu \mu$ & $\mu$ \\
$/$ fwz+ a & OCP & $\begin{array}{c}\text { IDENT } \\
\text { IO (V) }\end{array}$ & $\begin{array}{c}\text { MAX-t } \\
\text { Hypo (C) }\end{array}$ & $\begin{array}{c}\text { DEP-Rt } \\
\text { Hypo (C) }\end{array}$ & $*$ GEM \\
\hline a. faw.wuuz & $* !$ & & & & $*$ \\
\hline b. faw.wiiz & & $* !$ & & & $*$ \\
\hline c. fay.yuuz & & & $*$ & $*$ & $*$ \\
\hline
\end{tabular}

The behavior of glide-medial roots where the glide is [y] further confirms that the failure of the underlying glide to appear in the hypocoristic is a matter of avoiding violation of the OCP. These roots behave just like sound triconsonantal roots in forming Pattern I hypocoristics. In this group, the underlying glide [y] appears in the hypocoristic. Representative examples are repeated in (23):

(23) Names with medial [y]

\begin{tabular}{|c|c|c|c|}
\hline & Name & Hypocoristic & Root \\
\hline a. & bayaan & Bayyuun & /byn \\
\hline b. & Saayfa & Sayyuuf & $/$ Syf/ \\
\hline
\end{tabular}




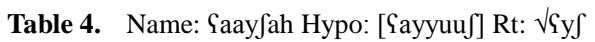

\begin{tabular}{|c|c|c|c|c|c|c|c|}
\hline 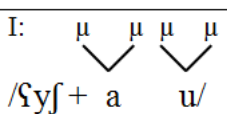 & $\begin{array}{c}\text { MAX-Rt, } \\
\text { Hypo } \\
\text { (C) }\end{array}$ & $\begin{array}{c}\text { DEP-Rt, } \\
\text { Hypo } \\
\text { (C) }\end{array}$ & $\begin{array}{c}\text { MAX-IO } \\
(\mu)\end{array}$ & $\begin{array}{l}\text { IDENT- } \\
\text { IO (V) }\end{array}$ & $\begin{array}{c}\text { Align } \\
\text { (Rt, L, } \\
\text { Hypo, L) }\end{array}$ & $\begin{array}{c}\text { Align } \\
\text { (Rt, R, } \\
\text { Hypo, R) }\end{array}$ & *GEM \\
\hline a. $\quad$ ९ay.yuu & & & & & & & $*$ \\
\hline b. Sa.yuu & & & $* !$ & & & & \\
\hline c. $\quad$ Say.fuu & & & & & & $* !$ & \\
\hline d. Suy.yaa & & & & $* ! *$ & & & $*$ \\
\hline e. maS.yuuf & & $*$ & & & & & \\
\hline may.yuuf & $*$ & * & & & & & \\
\hline
\end{tabular}

The impermissible sequence *[wuu] does not arise in the examples in (23) because the glide in these names is [y]; it serves as the onset for the vowel [uu] of the hypocoristic pattern, but since it is not homorganic with the vowel of the pattern, the structure is well formed and these roots are treated as if they were regular triconsonantal roots. The same ranking in (18) holds here. This is shown in Table 4.

It is evident from Table 4 that given the input and the undominated constraints ((8)-(17)), the actual form is the only candidate that satisfies all of the constraints. The other candidates are excluded because of different fatal violations that have been discussed for sound triconsonantal roots. The OCP has no role in deciding hypocoristics of $y$-medial roots just like in sound triconsonantal roots. No new ranking is established in this case.

The upshot of the discussion is that glide-medial roots behave just like sound triliteral roots, except when the medial glide is $[\mathrm{w}]$, in which case, the name fails to form Pattern I hypocoristics because of violation of the OCP.

\subsection{The Role of Syllable Structure: Pattern II Hypocoristics}

The analysis provided here is along the same lines as that in Abu-Mansour [3], which offers the first formal analysis of this pattern. However, Abu-Mansour [3] treats Pattern I and Pattern II as two unrelated patterns, and fails to uncover the underlying similarities in their structure. The analysis also misses the fact that there is a division of labor between the two patterns. Generally, Pattern II is followed mainly by those names that fail to follow Pattern I, i.e. glide-final roots whether the glide is [y] or [w] (cf. Section 2.3). These names represent the majority of names that follow this pattern.

The same input proposed for Pattern I hypocoristics is assumed for Pattern II. The actual name provides the base from which native speakers factor out the consonantal root. In addition to the root consonants, the vowels of the pattern [aa] and [uu] form the other part of the input, exactly the same as the input to Pattern I.

Two characteristics differentiate this pattern from Pattern I, and need to be accounted for in term of constraints. First, this pattern ends in an open syllable, and second, this syllable is always light. The first of these differences will be the result of one of the faithfulness constraints ranking low in the grammar of this pattern.

As for the short vowel in the final syllable of the pattern, it follows from an independent characteristic of Arabic including MA, where vowels in final position are realized short unless they represent suffixes [17]. Therefore, no special ranking is required to account for the short vowel in the second syllable of Pattern II hypocoristics, and will be left out of all tables.

In addition, we adopt a constraint proposed by Rosenthall [18] to account for the distribution of vowels and glides in Standard Arabic. This is given in (24):

\section{(24) *ADJHIVOC ([18]: 411)}

No two adjacent high vocoids in the same syllable.

The constraint in (24) is specific to Arabic syllable structure. This constraint prohibits two adjacent high vocoids in the same syllable discussed in Rosenthall [18]. Rosenthall observes, 'onset-plus-vowel sequences *[wi], *[yu]; vowel-plus-coda sequences *[uy], *[iw]; and vowel sequences [ui], [iu] are prohibited in the same syllable. These sequences are marked because adjacent syllable positions have a sonority plateau' ([18]: 411). Rosenthall extends this constraint to include not only tautosyllabic sequences but also to any sequence of high vocoids.

$\mathrm{T}$ The constraint in (24) will figure prominently in the account of hypocoristics related to glide-final roots. However, our use of (24) in accounting for the hypocoristic data will depart slightly from Rosentall's use of the constraint. In MA, the restriction on adjacent high vocoids is restricted to tautosyllabic sequences that are also tautomorphemic. Thus, the constraint in (24) will not rule out sequences like [nis.yu] < /nisy-u/ 'they forgot' and [ram.yi] </ramy-i] 'my throwing' where [u] and [i] are tautosyallbic, but they represent independent morphemes, a subject and a possessive pronoun, respectively. We express the modified constraint in (25):

\section{(25) *ADJHIVOC (Tautomorphemic)}

\section{(Based on [18]: 411)}

No two adjacent tautomorphemic high vocoids in the same syllable.

We start with the roots that end in $[y],(5 c$ and d). The input to Pattern II forms includes the consonantal root and the two heavy syllables. All the constraints that constitute 
part of the grammar of Pattern I hypocoristics will be shown to be active in the derivarion of Pattern II. First, the ranking in (26) and the interaction in Table 5 establish the fact that Pattern II hypocoristics end in an open syllable. In Table 5, candidate (a) violates the restriction on two high vocoids by being faithful to the input glide [y]; however, it obeys the constraint at the right edge of the hypocoristic by parsing [y]. Candidate (b) avoids this violation by deleting the glide. The long vowel in final position will not surface in accordance with the general restriction on final long vowels in the language. Candidate (b) emerges as optimal despite deletion of the underlying glide and misaligning the last consonant [y] of the root with the right edge of the hypocoristic. Pattern II is then the result of the high ranking of the markedness constraint in (25) demoting two of the faithfulness constraints, namely, MAX-Rt Hypo (C) and Align (Rt, R, Hypo, R), to a rank that is lower than the one it occupies in the grammar of Pattern I. This violation is an inherent property of Pattern II. It minimally distinguishes it from Pattern I.

(26) *ADJHIVoc (tautomorphemic) >> Max-Rt Hypo (C), Align, Rt, R, Hypo,R,

Table 5. Name: zakiyyah Hypo: [zak.ku] Rt: $\sqrt{z k y}$

\begin{tabular}{|l|c|c|c|c|}
\hline I: $\sim^{\mu} V^{\mu}$ & $\begin{array}{c}\text { *adjhivoc } \\
\text { (tautomorph) }\end{array}$ & $\begin{array}{c}\text { MAX-Rt } \\
\text { Hypo (C) }\end{array}$ & $\begin{array}{c}\text { Align } \\
\text { (Rt, R, } \\
\text { Hypo, R) }\end{array}$ \\
\hline zky+a $\mathrm{u} /$ & $* !$ & & \\
\hline a. zak.kuuy & $* !$ & $*$ & $*$ \\
\hline b. zak.ku & & $*$ \\
\hline
\end{tabular}

As mentioned above, in MA, the restriction on adjacent high vocoids is restricted to tautosyllabic sequences that are also tautomorphemic. This additional restriction is borne out by the two candidates considered below, namely, $*_{z a k . k u y}$ and $*_{z a k . y u}<u>$. Both fail to emerge as optimal because of their morphological structure. The same ranking in (26) holds here.

In Table 6 below, faithful parsing of the root glide [y] as a coda or an onset when combined with the vowel of the hypocoristic pattern [uu] creates a sequence of two high vocoids that are both tautosyllabic and tautomorphemic. Thus, both candidates (a) and (b) lose allowing (c) to emerge as the winning candidate despite its violation of the faithfulness constraint MAX-Rt Hypo (C). This further confirms the role of *ADJHIVOC (tautomorphemic) as a syllable structure constraint in the grammar of Pattern II hypocoristics.

Table 6. Name: zakiyyah Hypo.: [zak.ku] Rt: $\sqrt{ }$ zky

\begin{tabular}{|c|c|c|c|c|}
\hline 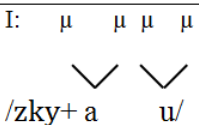 & $\begin{array}{c}\text { *ADJHIVOC } \\
\text { (tauto) }\end{array}$ & $\begin{array}{l}\text { MAX-Rt } \\
\text { Hypo (C) }\end{array}$ & $\begin{array}{c}\text { Align } \\
\text { (Rt, R, } \\
\text { Hypo, R) }\end{array}$ & *GEM \\
\hline a. zak.kuuy & $* !$ & & & \\
\hline b. zak.yu & $* !$ & & $*$ & \\
\hline c. zak.ku & & $*$ & * & $*$ \\
\hline
\end{tabular}

The same ranking obtained in (26) accounts for glide-final roots where the glide is [w]. This is illustratrd in Table 7 below.

Table 7. Name: Jaadyah Hypo.: [ $\left.\int \mathrm{addu}\right] \mathrm{Rt}: \sqrt{ } \int \mathrm{dw}$

\begin{tabular}{|c|c|c|c|c|c|}
\hline $\int_{/ \int \mathrm{d} w+\mathrm{a}}^{\mu} V_{\mathrm{u} /}^{\mu}$ & $\begin{array}{c}\text { "ADJHIVOC } \\
\text { (tauto) }\end{array}$ & OCP & $\begin{array}{l}\text { MAX-Rt } \\
\text { Hypo, (C) }\end{array}$ & $\begin{array}{c}\text { Align } \\
\text { (Rt, R, } \\
\text { Hypo, R) }\end{array}$ & ${ }^{*} \mathrm{GEM}$ \\
\hline a. Jad.duuw & *! & *! & & & \\
\hline b. Jad.duuy & *! & & * & & \\
\hline c. fad.du & & & * & $*$ & $*$ \\
\hline
\end{tabular}

\section{Similarities between Pattern I and Pattern II Hypocoristics}

Section 3.3 shows that the differences between the two patterns can be summarized in two points. Pattern II does not parse the final glide because of restrictions on syllable structure in the language. It does not align the final glide with the right edge of the hypocoristic either. The combined result of the two violations is that this pattern ends in an open syllable. However, the two patterns are more similar than different as the following discussion shows.

We use the case of names associated with biconsonantal roots to explain. As mentioned earlier, this group of names may form Pattern I hypocoristics, however, Pattern II is more common ((2.2) and (2.3)). This section will focus on exposing the similarities between the two patterns, capitalizing on the fact that they are two variants of one pattern. The similarities will be cast in terms of OT constraints. The ranking in (27) and Table 8 show the constraint interaction of Pattern I hypocoristics of the name hanaan and the emergence of Pattern II as one of the candidates in the interaction. In Table 8 below, the actual hypocoristic is candidate (e); it obeys all undominated constraints; it only violates *GEM which ranks low in the grammar of Pattern I hypocoristics. Note that candidate (d), violates the alignment constraint at the right edge of the hypocoristic and is thus excluded as optimal for Pattern I hypocoristic; however, it has the exact $\mathrm{C}_{1} \mathrm{aC}_{2} \mathrm{C}_{2} \mathrm{u}$ template of Pattern II. This is exactly the candidate that will emerge as optimal in Pattern II hypocoristics.

\section{(27) ONSET, MAX-IO ( $\mu$ ), Align (Rt, R, Hypo, R), *VV >> *GEM}

Table 8. Name: hanaan Hypo: [ hannuun] Rt: $\sqrt{\hbar n}$

\begin{tabular}{|l|c|c|c|c|c|}
\hline I: $\mu{ }^{\mu} \mu$ & ONSET & $\begin{array}{c}\text { MAX-IO } \\
(\mu)\end{array}$ & $\begin{array}{c}\text { Align } \\
\text { (Rt, R, } \\
\text { Hypo, } \mathrm{R})\end{array}$ & *VV & *GEM \\
\hline a. ha.nuun & & $* !$ & & $*$ & \\
\hline b. haa.nuun & & & & $* *$ & \\
\hline c. han.uun & $* !$ & & & $*$ & \\
\hline d. han.nu & & & $* !$ & & \\
\hline e. han.nuun & & & & $*$ & $*$ \\
\hline
\end{tabular}

(28) ONSET, *VV, MAX-IO $(\mu)>>$ Align (Rt, R, Hypo, $\mathrm{R})$, *GEM 


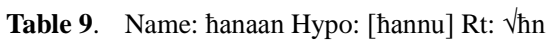

\begin{tabular}{|c|c|c|c|c|c|}
\hline I: $\vee_{/ \hbar n+a}^{\mu} V_{u /}^{\mu}$ & ONSET & *VV & $\begin{array}{c}\text { MAX-IO } \\
(\mu)\end{array}$ & $\begin{array}{c}\text { Align } \\
\text { (Rt, R, } \\
\text { Hypo, R) }\end{array}$ & *GEM. \\
\hline a. ћan.u & $* !$ & & & $*$ & \\
\hline b. ћaa.nu & & $* !$ & & * & \\
\hline c. ћa.nu & & & $* !$ & * & \\
\hline d. ћan.nu & & & & * & $*$ \\
\hline
\end{tabular}

Table 9 is an illustration of the constraint ranking in (28) that accounts for Pattern II hypocoristics of names related to biconsonantal geminate roots. The low ranking of the alignment constraint in the grammar of Pattern II is borne out by the optimal candidate (d); it minimally violates the low ranking *GEM and the constraint that aligns the last root consonant with the right edge of the hypocoristic.

However, the similarities between the two patterns outnumber the differences. Just like Pattern I, Pattern II realizes the first syllable in the hypocoristic as a CVC through the ranking $* V V$ V > $>$ GEM. Satisfaction of the faithfulness constraints Max-Rt Hypo C, Dep-Rt Hypo C, and MAX-IO $(\mu)$ and the markedness constraints ONSET and $* \mathrm{VV}$ is among the shared properties of the two patterns.

\section{Conclusions}

The paper offers an explanation for the failure of names related to glide-medial and glide-final roots to form Pattern I hypocoristics without recourse to the idea of an output root. This failure is attributed to the effects of two constraints, the OCP and the constraint against having two adjacent high vocoids in the same syllable. Both constraints are well motivated and form a basic part in the phonology of Arabic in general.

The present analysis has the advantage of relating Pattern I and Pattern II of hypocoristics showing their minimal differences in terms of constraint ranking. Both patterns have the same constraints ranking with the exception of the alignment constraint at the right edge of Pattern II hypocoristics and the lack of parsing the root final glide because of syllable structure constraints.

The analysis provides evidence for the importance of the template in MA morphology. Satisfaction of the template was crucial in the grammar of both patterns. However, the template is not stipulated, rather it results from the interaction of the various families of constraints.

\section{REFERENCES}

[1] Abu-Mansour, Mahasen Hasan. 1995. Arabic names and nicknames: A linguistic study. Talk presented at the twenty second LACUS meeting. Trinity University, San Antonio, Texas.

[2] Abu-Mansour, Mahasen Hasan. 2000. An OT analysis of
Arabic hypochoristics. Talk given at the MIT Phonology Circle, Cambridge, December 1, 2000.

[3] Abu-Mansour, Mahasen Hasan. 2010. An Optimality-Theor etic Account of Hypochoristic Formation in Makkan Arabic. Talk presented at the twenty fourth symposiums on Arabic linguistics, April 9-11, 2010. University of Texas at Austin.

[4] Zuwaydeh, Bushra Adnan, and Stuart Davis. 1999. Hypocoristic Formation in Ammani-Jordanian Arabic. In Perspective on Arabic Linguistics XII, ed. Elabbas Benmamoun, 113-139. Philadelphia: John Benjamins.

[5] Davis, Stuart, and Bushra Adnan Zawaydeh. 1999. A Descriptive Analysis of Hypocoristics in Colloquial Arabic. Languages and Linguistics 3: 83-98.

[6] Farwaneh, Samira. 2007. Hypochoristics Revisited: Challenging the Primacy of the Consonantal Root. In Perspectives on Arabic Linguistics $X X$, ed. Mustapha Mughazy 25-50. Amsterdam: John Benjamins.

[7] McCarthy, John and Alan Prince.1995. Faithfulness and Reduplicative Identity. In University of Massachusetts Occasional Papers, vol. 18: Papers in Optimality Theory, ed. J. N. Beckman, L. Walsh Dickey \& S. Urbanczyk, 249384. Amherst: University of Massachusetts.

[8] McCarthy, John. 1995. Extensions of Faithfulness: Rotuman Revisited. Amherst: University of Massachusetts, MS.

[9] McCarthy, John and Alan Prince.1993b. Generalized Alignment. In Year book of morphology, ed. Geert Booij and Jaap van Marle , 79-153. Dordrecht: Kluwer.

[10] Prince, Alan and Paul Smolensky. 1993. Optimality Theory: Constraint Interaction in Generative Grammar. New Brunswick, NJ: Rutgers University Center for Cognitive Science.

[11] McCarthy, John and Alan Prince. 1993a. Prosodic Morphology I: Constraint Interaction and Satisfaction. Amherst \& New Brunswick: University of Massachusetts \& Rutgers University, MS.

[12] Younes, Munther. 1995. on Vowel Shortening in Palestinian Arabic. In Perspectives on Arabic Linguistics VII, ed. Mushira Eid, 57-171. Amsterdam: John Benjamins.

[13] Leben, William. 1973. Suprasegmental Phonology. PhD dissertation, MIT, Cambridge, MA.

[14] McCarthy, John. 1979. Formal Problems in Semitic Phonology and Morphology. PhD [14] McCarthy, John. 1979. Formal Problems in Semitic Phonology and Morphology. PhD dissertation, MIT, Cambridge, MA.

[15] McCarthy, John. 1986. OCP Effects: Gemination and Antigemination. Linguistic inquiry 17: 207-63.

[16] Yip, Moira. 1988. The Obligatory Contour Principle and Phonological Rules: A Loss of Identity. Linguistic Inquiry 19: 65-100.

[17] McCarthy, John. 2005. The length of stem-final vowels in colloquial Arabic. In Perspectives on Arabic Linguistics XVII-XVIII, ed. Muhammad Alhawary and Elabbas Benmamoun, 1- 26. Amsterdam: John Benjamins.

[18] Rosenthall, Sam. 2006. Glide Distribution in Classical Arabic Verb Stems. Linguistic Inquiry 37: 405- 440 